УДК 616.89-008.1-055.2:616.85:616.891.4:613.64:62.168.7:622.87

Для цитирования: Синеуцкая Е.О., Володин Б.Ю., Петров Д.С. Клинические характеристики пациентов с соматоформными психическими расстройствами, работающих в атомной промышленности. Сибирский вестник психиатрии и наркологии. 2018; 4 (101): 61-67. https://doi.org/10.26617/1810-3111-2018-4(101)-61-67

\title{
Клинические характеристики пациентов с соматоформными психическими расстройствами, работающих в атомной промышленности
}

\author{
Синеуцкая Е.О. ${ }^{1}$, Володин Б.Ю.', Петров Д.С. ${ }^{2}$ \\ ${ }^{1}$ Центр изучения расстройств пищевого поведения \\ Россия, 125367, Москва, Полесский проезд 16, стр.6 \\ ${ }^{2}$ Рязанский государственный медицинский университет имени академика И.П. Павлова \\ Россия, 390026, Рязань, ул. Высоковольтная, д. 9
}

\section{PEЗЮME}

Расстройствами психики, наиболее часто встречающими в условиях атомного производства, являются пограничные психические расстройства. Проблема охраны здоровья работников атомной промышленности имеет особое значение, так как его сохранность является одной из важннейших составляющих их качества жизни и сохранения трудоспособности. В связи с воздействием множества факторов условий работы сотрудники атомного производства находятся в состоянии повышенной ответственности, нервно-эмоционального напряжения, увеличивающих риск возникновения невротических расстройств. С целью их раннего выявления и последующей разработки предложений по профилактике и лечению нервно-психических заболеваний среди сотрудников атомной промышленности нами была проведена данная научноисследовательская работа. Цель исследования - изучение психопатологических расстройств у 60 женщин с соматоформными расстройствами, поступивших на стационарное лечение в ФГБУЗ ЦПБ ФМБА России. Основная группа состояла из 30 пациенток с данным диагнозом, работающих на атомном производстве во вредных и (или) опасных условиях труда. Контрольная группа была представлена 30 женщинами с такими же расстройствами, занятыми в обычных условиях труда, не связанных с вредностью или опасностью. Результаты. У пациенток с соматоформными расстройствами, работающих в опасных и (или) вредных условиях труда, выявляются пять клинических синдромов: тревожный, астенический, психовегетативный, алгический, сенестопатический. Астенический, сенестопатический и алгический синдромы значимо превалируют у женщин основной группы, в то время как признаки тревожного синдрома статистически достоверно чаще встречаются у лиц контрольной группы. В группе с опасными условиями труда пациентки достоверно чаще страдают от повышенной утомляемости, раздражительности, слабости, дневной сонливости, слезливости, гиперчувствительности к внешним раздражителям, чем женщины, работающие в обычных условиях труда. В структуре алгического синдрома у основной категории женщин статистически значимо чаще встречается головная боль. В рамках сенестопатического синдрома «ощущение жара» достоверно в большей степени обнаруживается у лиц основной группы. Выводы: результаты проведенного исследования смогут помочь разработать конкретные организационные и лечебнопрофилактические программы для пациентов с соматоформными расстройствами, работающими в условиях атомной промышленности.

Ключевые слова: психопатологические нарушения, соматоформные психические расстройства, атомная промыш-
ленность.

\section{ВВЕДЕНИЕ}

Наиболее часто встречающимися психическими нарушениями на производстве являются пограничные психические расстройства. Их распространенность, согласно данным различных авторов, колеблется в широких пределах от 10 до 590 случаев на 1000 работающих [1]. Во многих работах обсуждается, что большое число пациентов с указанными расстройствами не получают специализированной и своевременной помощи, поскольку обращаются к врачам соматического профиля, не имеющим специального опыта в лечении таких больных [2, 3, 4, 5, 6]. Причины этого разнообразны: страх стигматизации, опасения потерять работу, отсутствие объективной информации о побочных действиях психофармакотерапии [7, 8]. Особое значение приобретает проблема охраны здоровья работников атомной промышленности, так как его сохранность является одной из важнейших составляющих качества жизни и сохранения трудоспособности [9]. На персонал, работающий в условиях вредных и (или) опасных производственных факторов, оказывают влияние [10]: 1) химические вещества; 2) физические факторы: ионизирующие излучения, радиоактивные вещества и другие источники ионизирующих излучений, неионизирующие излучения, электромагнитное излучение, ультрафиолетовое излучение, вибрация, производственный шум, ультразвук, инфразвук, пониженная и повышенная температуры воздуха в производственных помещениях и на открытой территории, тепловое излучение, повышенное и пониженное давление окружающей газовой и водной среды, световая среда (искусственное и естественное освещение), пониженная гравитация; 3) физические перегрузки: физическая динамическая нагрузка, масса поднимаемого и перемещаемого груза вручную, стереотипные рабочие движения, статическая нагрузка, рабочая поза, наклоны корпуса, перемещение в пространстве; 4) сенсорные нагрузки: работы с оптическими приборами (микроскопами, лупами и пр.). 
Таким образом, сотрудники атомного производства находятся в состоянии повышенной ответственности, нервно-эмоционального напряжения, увеличивающих риск возникновения невротических расстройств. До настоящего времени практически отсутствуют сведения о распространенности, клинико-психологической картине нервно-психических расстройств у лиц, профессионально занятых на атомном производстве [1].

С целью раннего выявления невротических расстройств и последующей разработки предложений по профилактике и лечению нервно-психических заболеваний среди сотрудников атомной промышленности нами и была проведена данная научноисследовательская работа.

\section{ЦЕЛЬ ИССЛЕДОВАНИЯ}

Выявить клинические особенности соматоформных расстройств у работников вредных и (или) опасных условий труда.

\section{МАТЕРИАЛ И МЕТОДЫ}

Проведенное нами исследование выполнено на базе клинической больницы ФГБУЗ ЦПБ ФМБА России. Обследование проводилось в двух группах пациенток: основной, состоящей из женщин, работающих во вредных и (или) опасных условиях труда, и в контрольной группе, состоявшей из лиц, работающих в обычных условиях, не имеющих ничего общего с атомным производством. Каждая группа включала по 30 пациенток в возрасте от 19 до 57 лет. Все респонденты проконсультированы научными сотрудниками больницы.

\section{Опасные условия}

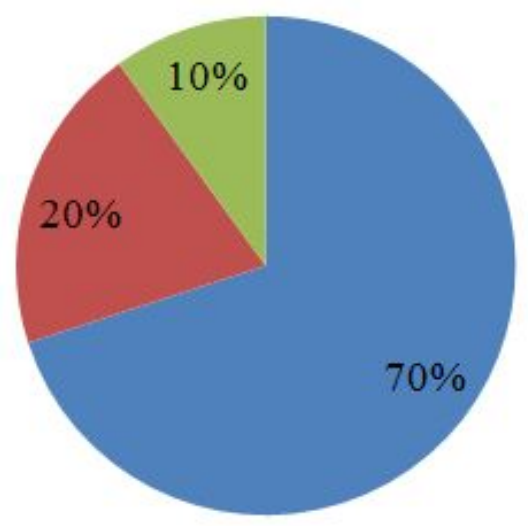

\section{Обычные условия}

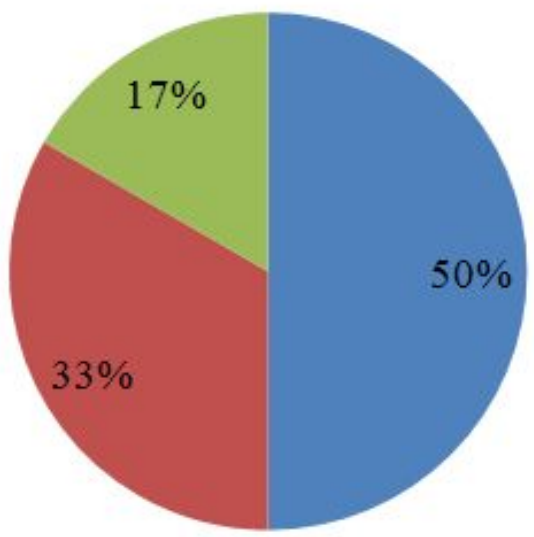

Основной метод исследования - клиникопсихопатологический. Диагностика проводилась в соответствии со стандартом Международной классификации болезней и проблем, связанных со здоровьем, 10-го пересмотра (МКБ-10).

Обследуемые пациентки обеих групп страдали соматоформными расстройствами: соматизированное расстройство (F45.0), ипохондрическое расстройство (F45.2) и соматоформная дисфункция вегетативной нервной системы (F45.3).

Обработка результатов проводилась с применением стандартных программ статистики. При математическом анализе был использован критерий достоверности различий: $\varphi^{*}$-критерий Фишера, непараметрический критерий Манна-Уитни.

\section{РЕЗУЛЬТАТЫ И ОБСУЖДЕНИЕ}

В ходе исследования выявлено, что в группе респондентов, занятых в опасных и вредных условиях труда, большинство обследованных страдало соматизированным расстройством (21 пациентка - 70\%), в 3 раза реже зарегистрировано ипохондрическое расстройство (6 - 20\%), с минимальной частотой выявлена соматоформная дисфункция вегетативной нервной системы $(3-10 \%)$.

Среди работающих в обычных условиях диагностические категории распределились следующим образом: соматизированное расстройство - 15 женщин $(50 \%)$, ипохондрическое расстройство - 10 (33\%), соматоформная дисфункция вегетативной нервной системы - 5 (17\%) (рис. 1).

\section{Р и с у н о к 1 . Распределение соматоформных расстройств в группах пациенток}

В ходе исследования у пациенток выявлена различная клинико-синдромальная картина заболеваний. Выраженность тревожного, астенического, алгического, психовегетативного и сенестопатического синдромов представлена в таблице 1. Как видно из таблицы, исследуемые группы достоверно отличаются по выраженности всех синдромов, кроме психовегетативного (рис. 2). Показано, что выраженность астенического (при $\mathrm{p}<0,01$ ), болевого и сенестопатического синдромов достоверно $(p<0,05)$ выше в основной группе (опасные условия труда). В то же время выраженность тревожного синдрома в основной группе оказалась ниже ( $<<0,01)$, чем в контрольной группе (обычные условия труда). Как указывает Н.Н. Пуховский (2004), для лиц, занятых профессиональной деятельностью в экстремальных ситуациях, свойственно переживание тревоги-опасности, и чрезвычайно выраженная тревога может рассматриваться как естественная реакция на опасную обстановку 
Встречаемость клинических проявлений в исследованных группах [Median (LQ; UQ)]

Т а б л и ц а 1

\begin{tabular}{|c|c|c|c|c|c|}
\hline \multirow[t]{2}{*}{ Синдром } & \multicolumn{2}{|c|}{\begin{tabular}{|c|} 
Пациентки-работницы опас- \\
ных условий труда $(\mathrm{n}=30)$
\end{tabular}} & \multicolumn{2}{|c|}{$\begin{array}{l}\text { Пациентки-работницы обычных } \\
\text { условий труда (контроль) }(\mathrm{n}=30)\end{array}$} & \multirow[t]{2}{*}{$\begin{array}{l}\text { p-уровень } \\
\text { U-критерия }\end{array}$} \\
\hline & $\mathrm{M}$ & Md; LQ-UQ & $\mathrm{M}$ & Md; LQ-UQ & \\
\hline Тревожный & 0,87 & 1,$00 ; 0,00$ & 1,53 & 1,$00 ; 1,00$ & $<0,01 * *$ \\
\hline Астенический & 5,57 & 6,$00 ; 0,00$ & 2,87 & 3,$00 ; 2,75$ & $<0,01 * *$ \\
\hline Психовегетативный & 2,60 & 3,$00 ; 0,70$ & 2,83 & 3,$00 ; 1,00$ & $>0,05$ \\
\hline Алгический & 1,47 & 1,$50 ; 0,04$ & 1,10 & 1,$00 ; 0,00$ & $<0,05^{*}$ \\
\hline Сенестопатический & 1,33 & 1,$00 ; 0,01$ & 0,50 & 0,$00 ; 1,00$ & $<0,05^{*}$ \\
\hline
\end{tabular}

П р и м е ч а н и е. M - среднее арифметическое по группе, Md - Медиана, LQ-UQ - интерквартильный размах, ** $\mathrm{p}<0,01, *$ - $<<0,05$ при сравнении с контрольной группой по U-критерию Манна-Уитни для независимых групп.

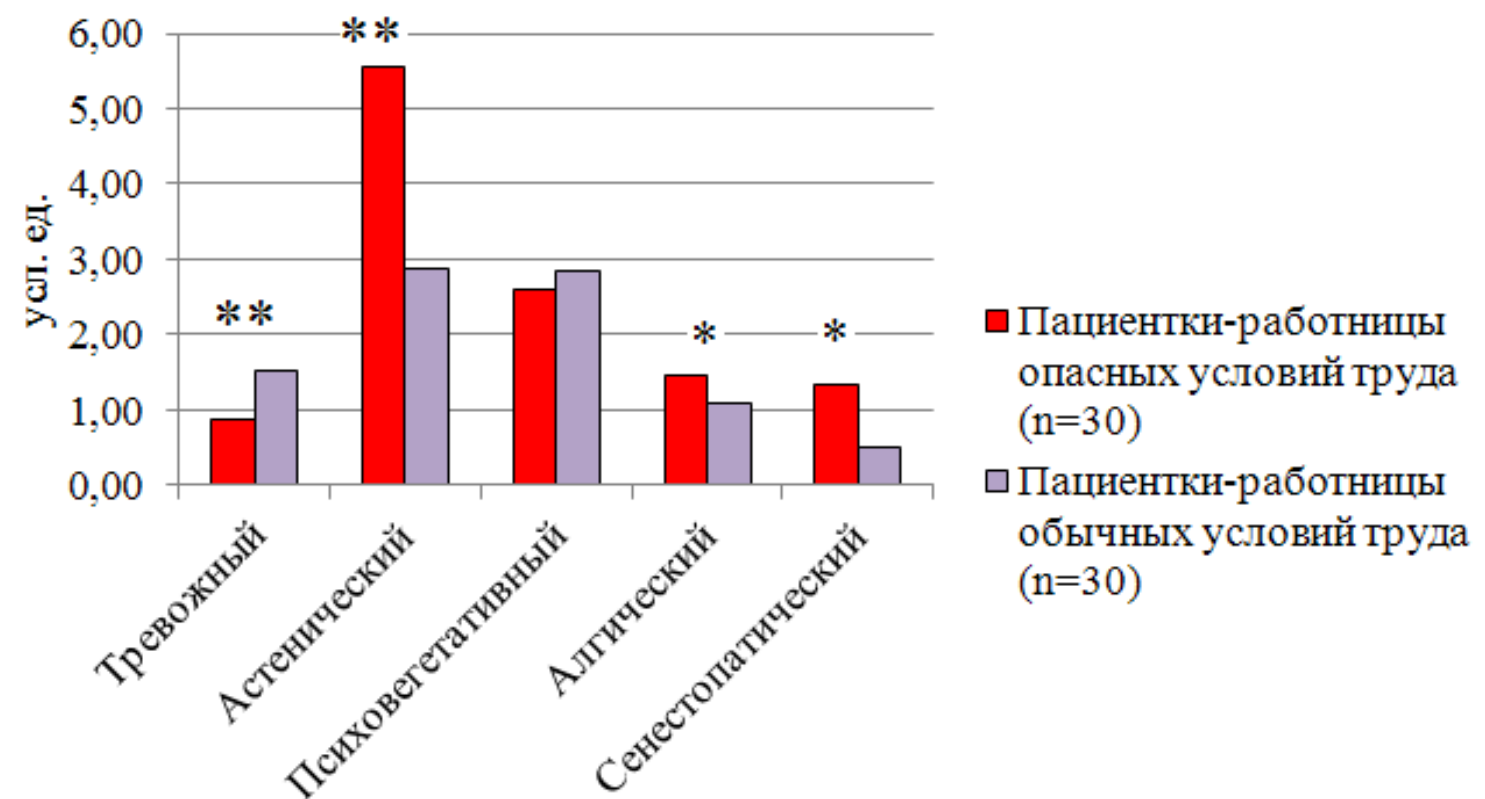

Синдромы

\section{Р и с у н о к 2. Встречаемость клинических проявлений в исследованных группах}

Однако недостаточность адаптационных ресурсов может повлечь за собой возникновение ощущения угрозы, нарастание тревоги и эмоциональной напряженности. Психологические особенности людей, работающих на атомных предприятиях, таковы, что работники могут быть закрыты для контакта и не заинтересованы раскрывать жалобы из-за нежелания потерять работу [12]. Таким образом, тревога, переходя на соматический уровень, трансформируется в телесные симптомы и может рассматриваться как один из факторов, провоцирующих развитие соматоформных психических расстройств $[8,13,14$, $15,16]$. Нельзя исключить вероятность того, что именно этот процесс объясняет меньший уровень тревоги у пациенток основной группы, где в силу объективных причин, связанных с вредными и (или) опасными условиями труда, он должен быть выше, и большую выраженность проявлений астенического и сенестопатического синдромов. Для более полной характеристики рассмотрим сравнение частот встречаемости симптомов в обеих группах по каждому синдрому (табл. 2, 3, 4, 5, 6).
В рамках тревожного синдрома повышенный уровень тревоги, различные ипохондрические переживания, беспокойство о будущем наблюдались у меньшего числа женщин, работающих во вредных условиях труда, чем у работниц обычного производства (табл. 2). Однако достоверных отличий внутри тревожного синдрома не обнаружено. У пациенток основной и контрольной групп тревога характеризовалась жалобами на ухудшение здоровья, чувство физического и психологического дискомфорта, спровоцированного тяжелым ожиданием неясной угрозы и беспокойством о будущем, неприятные телесные ощущения, двигательное беспокойство и суетливость, внутреннее напряжение.

В структуре астенического синдрома у женщин обеих исследуемых категорий выявлены такие симптомы, как вспыльчивость, повышенная возбудимость и выплеск негативных реакций, быстро сменяющиеся наступающей вслед за эмоциональным взрывом истощаемостью, а также несдержанность аффекта, непереносимость громких звуков, яркого света и резких запахов, снижение работоспособности (табл. 3 ). 
Сравнительная характеристика симптомов тревожного синдрома в группах исследования

\begin{tabular}{|c|c|c|c|c|c|}
\hline \multirow[t]{3}{*}{ Симптом } & \multicolumn{4}{|c|}{ Пациентки-работницы } & \multirow{3}{*}{$\begin{array}{c}\varphi^{*}- \\
\text { критерий } \\
\text { Фишера }\end{array}$} \\
\hline & \multicolumn{2}{|c|}{ опасных условий труда $(\mathrm{n}=30)$} & \multicolumn{2}{|c|}{ обычных условий труда $(\mathrm{n}=30)$} & \\
\hline & абс. & $\%$ & абс. & $\%$ & \\
\hline Тревога о своем здоровье & 6 & $20,00 \%$ & 12 & $40,00 \%$ & $>0,05$ \\
\hline $\begin{array}{l}\text { Дискомфорт с ожиданием угрозы, } \\
\text { беспокойство о будущем }\end{array}$ & 9 & $30,00 \%$ & 16 & $53,00 \%$ & $>0,05$ \\
\hline Двигательное беспокойство, суетливость & 2 & $7,00 \%$ & 5 & $17,00 \%$ & $>0,05$ \\
\hline $\begin{array}{l}\text { Чувство внутреннего напряжения с ощущением } \\
\text { повышенного тонуса мышц }\end{array}$ & 9 & $30,00 \%$ & 13 & $43,00 \%$ & $>0,05$ \\
\hline
\end{tabular}

П р и м е ч а н и е к таблицам $2,3,4,5,6: * *-p<0,01, *-p<0,05$ при сравнении с контрольной группой по критерию точный тест Фишера.

Т а б ли ц а 3

Сравнительная характеристика симптомов астенического синдрома в группах исследования

\begin{tabular}{|c|c|c|c|c|c|}
\hline \multirow[t]{3}{*}{ Симптом } & \multicolumn{4}{|c|}{ Пациентки-работницы } & \multirow{3}{*}{$\begin{array}{c}\varphi^{*-} \\
\text { критерий } \\
\text { Фишера }\end{array}$} \\
\hline & \multicolumn{2}{|c|}{ опасных условий труда $(\mathrm{n}=30)$} & \multicolumn{2}{|c|}{ обычных условий труда $(\mathrm{n}=30$} & \\
\hline & абс. & $\%$ & абс. & $\%$ & \\
\hline Раздражительность & 25 & $83,00 \%$ & 7 & $23,00 \%$ & $<0,01 * *$ \\
\hline Слабость & 25 & $83,00 \%$ & 8 & $27,00 \%$ & $<0,01 * *$ \\
\hline Повышенная утомляемость и истощаемость & 29 & $97,00 \%$ & 21 & $70,00 \%$ & $<0,01 * *$ \\
\hline Неустойчивостью настроения & 20 & $67,00 \%$ & 20 & $67,00 \%$ & $>0,05$ \\
\hline Дневная сонливость & 23 & $77,00 \%$ & 10 & $33,00 \%$ & $<0,01 * *$ \\
\hline $\begin{array}{l}\text { Непереносимостью громких звуков, } \\
\text { яркого света, резких запахов }\end{array}$ & 25 & $83,00 \%$ & 10 & $33,00 \%$ & $<0,01 * *$ \\
\hline Слезливость & 20 & $67,00 \%$ & 10 & $33,00 \%$ & $<0,05^{*}$ \\
\hline
\end{tabular}

Т а б л и ц а 4 Сравнительная характеристика симптомов психовегетативного синдрома в группах исследования

\begin{tabular}{|c|c|c|c|c|c|}
\hline \multirow[t]{3}{*}{ Симптом } & \multicolumn{4}{|c|}{ Пациентки-работницы } & \multirow{3}{*}{$\begin{array}{c}\varphi^{*-} \\
\text { критерий } \\
\text { Фишера }\end{array}$} \\
\hline & \multicolumn{2}{|c|}{ опасных условий труда $(\mathrm{n}=30)$} & \multicolumn{2}{|c|}{ обычных условий труда $(\mathrm{n}=30)$} & \\
\hline & абс. & $\%$ & абс. & $\%$ & \\
\hline Повышенная потливость & 14 & $47,00 \%$ & 13 & $43,00 \%$ & $>0,05$ \\
\hline Сухость во рту & 12 & $40,00 \%$ & 7 & $23,00 \%$ & $>0,05$ \\
\hline $\begin{array}{l}\text { Жар, покраснения, «приливы горячих } \\
\text { и холодных волн» }\end{array}$ & 10 & $33,00 \%$ & 11 & $37,00 \%$ & $>0,05$ \\
\hline Тремор & 13 & $43,00 \%$ & 15 & $50,00 \%$ & $>0,05$ \\
\hline Чувство нехватки воздуха & 10 & $33,00 \%$ & 12 & $40,00 \%$ & $>0,05$ \\
\hline Сердцебиение & 17 & $57,00 \%$ & 20 & $67,00 \%$ & $>0,05$ \\
\hline Учащенное мочеиспускание & 2 & $7,00 \%$ & 7 & $23,00 \%$ & $>0,05$ \\
\hline
\end{tabular}

\section{Сравнительная характеристика симптомов алгического синдрома в группах исследования}

\begin{tabular}{|c|c|c|c|c|c|}
\hline \multirow{3}{*}{ Симптом } & \multicolumn{4}{|c|}{ Пациентки-работницы } & \multirow{3}{*}{$\begin{array}{c}\varphi^{*}- \\
\text { критерий } \\
\text { Фишера }\end{array}$} \\
\hline & \multicolumn{2}{|c|}{ опасных условий труда $(\mathrm{n}=30)$} & \multicolumn{2}{|c|}{ обычных условий труда $(\mathrm{n}=30)$} & \\
\hline & абс. & $\%$ & абс. & $\%$ & \\
\hline Головная боль & 14 & $47,00 \%$ & 1 & $3,00 \%$ & $<0,01 * *$ \\
\hline Боль в животе & 5 & $17,00 \%$ & 11 & $37,00 \%$ & $>0,05$ \\
\hline Боль в грудной клетке & 14 & $47,00 \%$ & 15 & $50,00 \%$ & $>0,05$ \\
\hline Боль в конечностях & 10 & $33,00 \%$ & 4 & $13,00 \%$ & $>0,05$ \\
\hline Боль в гениталиях & 1 & $3,00 \%$ & 2 & $7,00 \%$ & $>0,05$ \\
\hline
\end{tabular}

Т а б ли ц а 6 Сравнительная характеристика симптомов сенестопатического синдрома в группах исследования

\begin{tabular}{|c|c|c|c|c|c|}
\hline \multirow[t]{3}{*}{ Симптом } & \multicolumn{4}{|c|}{ Пациентки-работницы } & \multirow{3}{*}{$\begin{array}{c}\varphi^{*-} \\
\text { критерий } \\
\text { Фишера }\end{array}$} \\
\hline & \multicolumn{2}{|c|}{ опасных условий труда $(\mathrm{n}=30)$} & \multicolumn{2}{|c|}{ обычных условий труда $(\mathrm{n}=30)$} & \\
\hline & абс. & $\%$ & абс. & $\%$ & \\
\hline Ощущение жара & 16 & $53,00 \%$ & 4 & $13,00 \%$ & $<0,01 * *$ \\
\hline Ощущения покалывания & 10 & $33,00 \%$ & 8 & $27,00 \%$ & $>0,05$ \\
\hline Ощущение ползания мурашек & 9 & $30,00 \%$ & 2 & $7,00 \%$ & $>0,05$ \\
\hline Чувство наполнения внутренних органов & 3 & $10,00 \%$ & 1 & $3,00 \%$ & $>0,05$ \\
\hline Ощущение движения во внутренних органах & 2 & $7,00 \%$ & 0 & $0 \%$ & $>0,05$ \\
\hline
\end{tabular}


Обнаружены достоверно значимые отличия, указывающие на то, что в группе работниц с опасными условиями труда в атомной промышленности пациентки чаще страдают от повышенной утомляемости и истощаемости, раздражительности, слабости, дневной сонливости, слезливости, гиперчувствительности к внешним раздражителям, чем женщины, работающие в обычных условиях труда. При этом раздражительность нередко сопровождалась вспыльчивостью по малейшему поводу, что со слов респондентов негативно отражалось на качестве внутрисемейных и производственных отношений.

В то же время сравнительная оценка психовегетативного статуса пациенток не выявила достоверных статистических различий (табл. 4). Женщины обеих групп (с опасными и обычными условиями труда) с одинаковой частотой предъявляли жалобы на повышенную потливость, сухость во рту, жар, покраснения, «приливы горячих и холодных волн», тремор, чувство нехватки воздуха, изменение ритма сердцебиения, учащенное мочеиспускание, невротические нарушения функции желудка.

Алгический синдром был представлен жалобами на болевые ощущения разной локализации (в области головы, брюшной полости, грудной клетки, конечностей, половых органов) и различного характера (ощущения ноющего, давящего, пульсирующего, сжимающего, тянущего, распирающего, колющего характера) (табл. 5). Но лишь жалобы на головную боль имели статистические различия.

Цефалгии, вызывая снижение памяти и внимания, статистически значимо преобладали в основной группе женщин. Болевые ощущения характеризовались различным характером и локализацией. Их интенсивность, со слов пациенток, зависела от их психоэмоционального, а временами и физического состояния. Неприятные болевые ощущения в верхних и нижних конечностях, как правило, усиливались при движении, после физического или эмоционального напряжения, носили мигрирующий характер, сопровождались спонтанно возникающими ощущениями покалывания, онемения, жжения, ползания мурашек («иголочками колет», «мурашки бегают»). Жалобы на боли в области живота так же не были связаны с приемом пищи, а зависели от психоэмоционального состояния женщины. Они варьировали от «ощущения легкого дискомфорта» до «невыносимых спазмов», сопровождались неприятным вкусом во рту, рвотой, расстройством стула, ощущениями тяжести и переполнения.

Сенестопатический синдром включал в себя различные эмоционально описываемые ощущения: «жар в голове», «голову жжет», «сердце печет», «огонь в груди», «обдает горячими волнами грудь», в конечностях «покалывает», «горит кожа рук и ног», ощущения наполнения, движения и переливания во внутренних органах. Ощущения жара в различных частях тела значимо преобладали в основной группе пациенток (табл. 6).

\section{ЗАКЛЮЧЕНИЕ}

На основании результатов проведенного исследования можно сделать ряд обоснованных выводов.

У пациенток с соматоформными расстройствами, работающих в опасных и (или) вредных условиях труда, выявляются пять клинических синдромов: тревожный, астенический, психовегетативный, алгический, сенестопатический.

Астенический, сенестопатический и алгический синдромы значимо превалируют у женщин основной группы, в то время как признаки тревожного синдрома статистически достоверно чаще встречаются у женщин-работниц контрольной группы.

В группе работниц с опасными условиями труда пациентки достоверно чаще страдают от повышенной утомляемости, раздражительности, слабости, дневной сонливости, слезливости, гиперчувствительности к внешним раздражителям, чем женщины, работающие в обычных условиях труда.

В структуре алгического синдрома у основной категории женщин статистически значимо чаще встречается головная боль.

В рамках сенестопатического синдрома «ощущение жара» достоверно в большей степени обнаруживается у лиц основной группы.

Подводя заключительный итог, следует сказать, что проведенное исследование позволило выявить основные психопатологические синдромы и симптомы у женщин с соматоформными психическими расстройствами, работающих во вредных и (или) опасных условиях труда, что в дальнейшем сможет помочь разработать конкретные организационные и лечебно-профилактические программы в виде алгоритмов диагностики и терапевтической коррекции соматоформной патологии для работников атомной промышленности.

\section{КОНФЛИКТ ИНТЕРЕСОВ}

Авторы заявляют об отсутствии конфликта интересов в связи с публикацией данной статьи.

\section{ИСТОЧНИК ФИНАНСИРОВАНИЯ}

Авторы заявляют об отсутствии финансирования при проведении исследования.

\section{СООТВЕТСТВИЕ ПРИНЦИПАМ ЭТИКИ}

Работа соответствует этическим стандартам, разработанным в соответствии с Хельсинской декларацией ВМА (протокол заседания этического комитета при ФГБОУ ВО РязГМУ Минздрава России № 1 от 22.09.2014).

\section{ЛИТЕРАТУРА}

1. Положий Б.С., Шевцов А.Ю. Дифференцированные программы психотерапии пограничных психических расстройств у работников промышленности. Российский психиатрический журнал. 1999; 6: 20-22.

2. Аксенов М.М., Семке В.Я., Белокрылова М.Ф., Куприянова И.Е., Епанчинцева Е.М., Ветлугина Т.П., Иванова С.А., Гуткевич Е.В., Кусков М.В., Стоянова И.Я., Лебедева В.Ф., Рудницкий В.А., Перчаткина О.Э., Никитина В.Б., Васильева Н.А., Агарков А.А. Типология, конституциональнобиологические и клинико-динамические характеристики кризисных состояний при пограничных нервно-психических расстройствах. Сибирский вестник психиатрии и наркологии. 2009; 5 (56): 9-15. 
3. Бобров А.Е. Проблема психосоматических соотношений и некоторые методологические вопросы психопатологии. Сoциальная и клиническая психиатрия. 2017; 27 (1): 98-103.

4. Близнюк А.И. Психосоматическая патология, классические теории современные, концепции. Медицинские новости. 2014; 10 (241): 10-15.

5. Гусева И.В. Психологический стресс и соматические расстройства. Новое слово в науке: перспективы развития. 2015: 1 (3): 98-100.

6. Зорина С.А. Соматоформные расстройства в общеврачебной практике. Справочник врача общей практики. 2014; 9: 32 36.

7. Демчева Н.К., Орлова Н.В. Невротические расстройства у городского населения (клинико-эпидемиологический, фармакоэпидемиологический и организационный аспекты). Российский психиатрический журнал. 2011; 6: 42-50.

8. Погосов А.В., Богушевская Ю.В. Клинические, личностнопсихологические и социально-демографические факторы, препятствующие обращению больных соматизированными расстройствами за специализированной помощью. Сибирский вестник психиатрии и наркологии. 2017; 4 (97): 22-30.

9. Терехина О.В. Жизнестойкость и качество жизни работников атомной промышленности. Сибирский вестник психиатрии и наркологии. 2016; 3 (92): 81.

10. Приказ Минздравсоцразвития России от 12.04.2011 № 302н (ред. От 05.12.2014) «Об утверждении перечней вредных и (или) опасных производственных факторов и работ, при выполнении которых проводятся обязательные предваритель- ные и периодические медицинские осмотры (обследования), и Порядка проведения обязательных предварительных и периодических медицинских осмотров (обследований) работников, занятых на тяжелых работах и на работах с вредными и (или) опасными условиями труда».

11. Антухов А.В. Психическое здоровье работников особо опасного производства атомной промышленности : дис. ... к.м.н. Томск, 2010: 190.

12. Иванов В.В. Вопросы психогигиены и психопрофилактики на предприятии атомной промышленности. Екатеринбург: Банк культурной информации, 2015: 158.

13. Иванов С.Г. Самосознание больных с соматоформными расстройствами и его динамика в процессе психотерапии. Социальная и клиническая психиатрия. 2000; 2: 55-57.

14. Колесников Д.Б., Рапопорт С.И., Вознесенская Л.А. Современные взгляды на психосоматические заболевания. Клиническая медииина. 2014; 92 (7): 12-18.

15. Косенко В.Г., Красильников Г.Т., Косенко Н.А., Солоненко А.В., Янова О.А. Ипохондрические состояния и соматоформные расстройства. Психическое здоровье. 2013; 11 (90): 32-36.

16. Измеров Н.Ф., Липенецкая Т.Д., Матюхин В.В. Стресс на производстве как важная составляющая проблемы психического здоровья в обществе. Российский психиатрический журнал. 2005; 2: 10-14.

Поступила в редакцию 3.04.2018 Утверждена к печати 6.11.2018

Синеуцкая Екатерина Олеговна, врач-психиатр, психотерапевт.

Володин Борис Юрьевич, доктор медицинских наук, заведующий кафедрой клинической психологии и психотерапии.

Петров Дмитрий Сергеевич, доктор медицинских наук, заведующий кафедрой психиатрии и психотерапии ФдПО.

$\bowtie$ Синеуцкая Екатерина Олеговна, juna-rom@mail.ru

ДК 616.89-008.1-055.2:616.85:616.891.4:613.64:62.168.7:622.87

For citation: Sineutskaya E.O., Volodin B.Yu., Petrov D.S. Clinical characteristics of patients with somatoform mental disorders working in nuclear industry. Siberian Herald of Psychiatry and Addiction Psychiatry. 2018; 4 (101): 61-67. https://doi.org/10.26617/1810-3111-2018-4(101)-61-67

\title{
Clinical characteristics of patients with somatoform mental disorders working in nuclear industry \\ Sineutskaya E.O. ${ }^{1}$, Volodin B.Yu. ${ }^{2}$, Petrov D.S. ${ }^{2}$
}

${ }^{1}$ Center for the Study of Eating Disorder

Polessky proezd 16, p. 6, 125367, Moscow, Russian Federation

${ }^{2}$ Ryazan State Medical University named after Academician I.P. Pavlov

Vysokovoltnaya Street 9, 390026, Ryazan, Russian Federation

\begin{abstract}
Mental disorders, which are the most common ones in nuclear production, are borderline mental disorders. The problem of protection of health of workers of the nuclear industry is of special importance, as its safety is one of the most important components of their quality of life and ability to work. Due to the influence of many factors in working conditions, employees of nuclear production are in a state of increased responsibility, nervous and emotional stress, increasing the risk of neurotic disorders. For the purpose of their early detection and the subsequent development of suggestions on prevention and treatment of neuropsychiatric diseases among employees of the nuclear industry, we carry out this research work. The aim of this study is to study psychopathological disorders in 60 women with somatoform disorders admitted to the FGBUZ of the FMBA of Russia. The main group consisted of 30 patients with this diagnosis, working at nuclear production in harmful and (or) dangerous working conditions. The control group was represented by 30 women with the same disorders, employed in normal working conditions, not related to harm or danger. Results: In patients with somatoform disorders, working in harmful and (or) dangerous working conditions five clinical syndromes are identified: anxiety, asthenic, psychovegetative, alalgical, cenestopathic; asthenic, cenestopathic and alalgical syndromes are significantly prevalent in women of the main group, while the symptoms of anxiety syndrome are significantly more common in individuals of the control group; in the group with "dangerous working conditions", patients are significantly more likely to suffer from increased fatigue, irritability, weakness, daytime drowsiness, tearfulness, hypersensitivity to external stimuli than women working in "normal" working conditions; in the structure of the alalgic syndrome in the main category of women headache is statistically significantly more common; in the framework of cenestopathic syndrome "heat sensation" is reliably detected in the main group. Conclusions: The results of the study will
\end{abstract}


help to develop specific organizational and therapeutic-preventive programs for patients with somatoform disorders working in the nuclear industry.

\section{Keywords: psychopathological disorders, somatoform mental disorders, nuclear industry.}

\section{REFERENCES}

1. Polozhy B.S., Shevtsov A.Yu. Differencirovannye programmy psihoterapii pogranichnyh psihicheskih rasstrojstv u rabotnikov promyshlennoti [Differentiated programs of psychotherapy of borderline mental disorders in industrial workers]. Rossijskij psihiatricheskij zhurnal - Russian Journal of Psychiatry. 1999; 6: 20-22 (in Russian)

2. Axenov M.M., Semke V.Ya., Belokrylova M.F., Kupriyanova I.E., Epanchintseva E.M., Vetlugina T.P., Ivanova S.A., Gutkevich E.V., Kuskov M.V., Stoyanova I.Ya., Lebedeva V.F. Rudnitsky V.A., Perchatkina O.E., Nikitina V.B., Vasilieva N.A., Agarkov A.A. Tipologiya, konstitutsional'nobiologicheskie i kliniko-dinamicheskie kharakteristiki krizisnykh sostoyaniy pri pogranichnykh nervno-psikhicheskikh rasstroystvakh. [Typology, constitutional-biological and clinicaldynamic characteristics of crisis states in borderline neuromental disorders]. Sibirskii vestnik psikhiatrii i narkologii - Siberian Herald of Psychiatry and Addiction Psychiatry. 2009; 5 (56): 9-15. (in Russian).

3. Bobrov A.E. Problema psihosomaticheskih sootnoshenij nekotorye metodologicheskie voprosy psihopatologii [The problem of psychosomatic correlations and some methodological issues of psychopathology]. Social'naya i klinicheskaya psihiatriya - Social and Clinical Psychiatry. 2017; 27 (1): 98-103 (in Russian)

4. Bliznyuk A.I. Psihosomaticheskaya patologiya, klassicheskie teorii sovremennye, koncepcii [Psychosomatic pathology, classical theories, modern concepts]. Medicinskie novosti - Medical News. 2014; 10 (241): 10-15 (in Russian).

5. Guseva I.V. Psihologicheskij stress i somaticheskie rasstrojstva [Psychological stress and somatic disorders]. Novoe slovo $v$ nauke: perspektivy razvitiya - New Word in Science: Development Prospects. 2015: 1 (3): 98-100 (in Russian).

6. Zorina S.A. Somatoformnye rasstrojstva $\mathrm{v}$ obshchevrachebnoj praktike [Somatoform disorders in General medical practice]. Spravochnik vracha obshchej praktiki - Handbook for the General Practitioner. 2014; 9: 32-36 (in Russian).

7. Demcheva N.K., Orlova N.V. Nevroticheskie rasstrojstva u gorodskogo naseleniya (kliniko-ehpidemiologicheskij, farmakoehpidemiologicheskij i organizacionnyj aspekty) [Neurotic disorders in the urban population (clinical and epidemiological, pharmacoepidemiological and organizational aspects)]. Rossijskij psihiatricheskij zhurnal - Russian Journal of Psychiatry. 2011; 6: 42-50 (in Russian).

8. Pogosov A.V., Bogushevskaya Yu.V. Klinicheskie, lichnostnopsihologicheskie i social'no-demograficheskie faktory, prepyatstvuyushchie obrashcheniyu bol'nyh somatizirovannym rasstrojstvami za specializirovannoj pomoshch'yu [Clinical, personal-psychological and socio-demographic factors that prevent the treatment of patients with somatic disorders for specialized care]. Sibirskij vestnik psihiatrii i narkologii - Siberian Herald of Psychiatry and Addiction Psychiatry. 2017; 4 (97): 22-30 (in Russian).

9. Terekhina O.V. Zhiznestojkost' i kachestvo zhizni rabotnikov atomnoj promyshlennosti [Viability and quality of life of em- ployees of the nuclear industry]. Sibirskij vestnik psihiatrii $i$ narkologii - Siberian Herald of Psychiatry and Addiction Psychiatry. 2016; 3 (92): 81 (in Russian).

10. Prikaz Minzdravsocrazvitiya Rossii ot 12.04.2011 № 302n (red. Ot 05.12.2014) «Ob utverzhdenii perechnej vrednyh i (ili) opasnyh proizvodstvennyh faktorov i rabot, pri vypolnenii kotoryh provodyatsya obyazatel'nye predvaritel'nye i periodicheskie medicinskie osmotry (obsledovaniya), i Poryadka provedeniya obyazatel'nyh predvaritel'nyh i periodicheskih medicinskih osmotrov (obsledovanij) rabotnikov, zanyatyh na tyazhelyh rabotah i na rabotah s vrednymi i (ili) opasnymi usloviyami truda» [Order of the Ministry of health and social development of Russia dated 12.04.2011 № 302n (ed. by 05.12.2014) "About the approval of lists harmful and (or) dangerous production factors and works at which performance are mandatory preliminary and periodic medical examinations (surveys), and the Order of carrying out obligatory preliminary and periodic medical examinations (examinations) workers engaged in heavy work and work places with harmful and (or) dangerous working conditions»] (in Russian).

11. Antukhov A.V. Psihicheskoe zdorov'e rabotnikov osobo opasnogo proizvodstva atomnoj promyshlennosti : dissertaciya ... kandidata medicinskih nauk [Mental health of workers of especially dangerous production of the nuclear industry: thesis ... candidate of medical Sciences]. Tomsk, 2010: 190 (in Russian).

12. Ivanov V.V. Voprosy psihogigieny i psihoprofilaktiki na predpriyatii atomnoj promyshlennosti [Issues of mental health and psychological prevention at the enterprise of the nuclear industry]. Ekaterinburg: Bank of Cultural Information, 2015: 158 (in Russian).

13. Ivanov S.G. Samosoznanie bol'nyh s somatoformnymi rasstrojstvami i ego dinamika $\mathrm{v}$ processe psihoterapii [Self-awareness of patients with somatoform disorders and its dynamics in the process of psychotherapy]. Social'naya i klinicheskaya psihiatriya - Social and Clinical Psychiatry. 2000; 2: 55-57 (in Russian).

14. Kolesnikov D.B., Rapoport S.I., Voznesenskaya L.A. Sovremennye vzglyady na psihosomaticheskie zabolevaniya [Modern views on psychosomatic diseases]. Klinicheskaya medicina Clinical Medicine. 2014; 92 (7): 12-18 (in Russian).

15. Kosenko V.G., Krasil'nikov G.T., Kosenko N.A., Solonenko A.V., Yanova O.A. Ipohondricheskie sostoyaniya i somatoformnye rasstrojstva [Hypochondriac conditions and somatoform disorders]. Psihicheskoe zdorov'e - Mental Health. 2013; 11 (90): 32-36 (in Russian).

16. Izmerov N.F., Lipenetskaya T.D., Matyukhin V.V. Stress na proizvodstve kak vazhnaya sostavlyayushchaya problemy psihiche-skogo zdorov'ya $\mathrm{v}$ obshchestve [Stress at work as an important component of mental health problems in society]. Rossijskij psihiatricheskij zhurnal - Russian Journal of Psychiatry. 2005; 2: 10-14 (in Russian).

Received April 3.2018 Accepted November 6.2018

Sineutskaya Ekaterina O., psychiatrist, psychotherapist, Center for the Study of Eating Disorder, Moscow, Russian Federation.

Volodin Boris Yu., MD, Head of the Department of Clinical Psychology and Psychotherapy, Ryazan State Medical University named after Academician I.P. Pavlov, Ryazan, Russian Federation

Petrov Dmitry S., MD, Head of the Department of Psychiatry and Psychotherapy of the Faculty of Post-graduate Education, Ryazan State Medical University named after Academician I.P. Pavlov, Ryazan, Russian Federation.

$\bowtie$ Sineutskaya Ekaterina O., juna-rom@mail.ru 